\title{
REVIEW
}

\section{Treatment of refractory thyroid cancer}

\section{Amandine Berdelou', Livia Lamartina², Michele Klain ${ }^{3}$, Sophie Leboulleux' and Martin Schlumberger ${ }^{1}$ on behalf of the TUTHTYREF Network}

'Department of Nuclear Medicine and Endocrine Oncology, TUTHYREF (Tumeurs de la Thyroïde Réfractaires) Network, Gustave Roussy and University Paris-Saclay, Villejuif, France

2Department of Internal Medicine and Medical Specialties, Sapienza University of Rome, Rome, Italy

${ }^{3}$ Department of Advanced Biomedical Sciences, University of Naples 'Federico II', Naples, Italy

Correspondence should be addressed to M Schlumberger: martin.schlumberger@gustaveroussy.fr

\begin{abstract}
Distant metastases from thyroid cancer of follicular origin are uncommon. Treatment includes levothyroxine administration, focal treatment modalities with surgery, external radiation therapy and thermal ablation, and radioiodine in patients with uptake of $131 \mid$ in their metastases. Two-thirds of distant metastases become refractory to radioiodine at some point, and when there is a significant tumor burden and documented progression on imaging, a treatment with a kinase inhibitor may provide benefits.
\end{abstract}

\author{
Key Words \\ - radioactive iodine \\ - refractory thyroid cancer \\ tyrosine kinase inhibitor \\ - precision medicine \\ - risk stratification \\ - papillary thyroid cancer \\ - follicular thyroid cancer
}

Endocrine-Related Cancer (2018) 25, R209-R223

\section{Introduction}

Distant metastases from differentiated follicular-derived thyroid carcinoma occur in 6-7 patients/million population and are mostly located in lungs and bones. In contrast with the observed increasing incidence of small thyroid cancers, there is no evidence that their incidence changes with time. They are the main cause of thyroid cancer-related deaths, with mortality rates of $65 \%$ and $75 \%$ at 5 and 10 years after the diagnosis of the metastases (Casara et al. 1993, Ruegemer et al. 1988, Kitamura et al. 1999, Durante et al. 2006).

In recent years, major therapeutic advances have been achieved for metastatic thyroid cancers: aims of levothyroxine treatment have been better defined, thermal ablation and stereotactic external beam radiation are currently used, indications and limits of radioactive (RAI) iodine treatment have been clarified and new treatment modalities are available for radioiodine-refractory disease. This review is intended to describe these advances.

\section{Treatment of distant metastases}

Treatment of distant metastases includes levothyroxine treatment, focal treatment and RAI as first systemic treatment line in patients with RAI uptake in their metastases. There is no randomized clinical trial demonstrating the superiority of either RAI administration or TSH-suppressive thyroid hormone treatment for patients with distant metastases. Use of these treatments is supported only by retrospective cohort studies, and there are broad variations in acceptable 'standard of care' with respect to the aggressiveness of TSH suppressive therapy and to the frequency and amount of RAI to use. 
The objective of levothyroxine treatment in these patients is to maintain serum TSH below $0.5 \mathrm{IU} / \mathrm{L}$, because increased TSH level may stimulate thyroid cancer growth (Biondi \& Wartofsky 2014, Haugen et al. 2016). Whether serum TSH level should be undetectable is still a matter of discussion, because the benefits of subclinical thyrotoxicosis that are still not demonstrated have to be balanced in each patient with the risk of cardiovascular consequences. Focal treatment modalities for brain metastases may include surgery and stereotactic radiation therapy (rather than whole brain irradiation). In the past, focal treatment of bone metastases was based on surgery after embolization and external beam radiation therapy at palliative doses (Bernier et al. 2001, Durante et al. 2006). Percutaneous thermal ablation (radiofrequency- or cryoablation), cement injection and implementation of screws are currently used, because they are effective and are less aggressive than surgery (Deandreis et al. 2011b, Quan et al. 2012), and they may be combined with external beam radiation therapy at high doses delivered with a curative intent. Focal treatment for bone metastases is indicated when there are symptoms, neurologic or orthopedic complications or a high risk of such complications; it is also indicated when bone metastases are visible on CT scan or MRI, even in the presence of ${ }^{131}$ I uptake, because in such cases, RAI treatment alone will not control the disease. In the presence of a single or few bone metastases, focal treatments are performed with a curative intent (Bernier et al. 2001).

Two-thirds of DTC patients with bone metastases developed skeletal-related events within a year following the diagnosis of bone metastases (Farooki et al. 2012). Unfortunately, bone progression commonly occurs during systemic treatment with RAI or a kinase inhibitor, and bone-directed therapy should be considered in patients with multiple progressive and/or symptomatic bone metastases. In other solid tumors, bisphosphonates (especially IV infusion of zoledronic acid every 1-3 months) and the RANK-ligand-directed agent (monthly sub-cutaneous injection of denosumab) have been shown to delay time to occurrence of skeletal-related events and to improve symptoms with similar efficacy (Wardley et al. 2005, Coleman et al. 2012). Risks of these agents include hypocalcemia, prompting the concomitant use of supplemental calcium and vitamin D therapy, and non-healing oral lesions and jaw osteonecrosis that can be partially prevented with dental/oral evaluation and treatment before initiation of the treatment.

Two-thirds of patients with distant metastases have significant RAI uptake. They are treated with ${ }^{131}$ I either with an empiric activity of $3700-7400 \mathrm{MBq}$ (100-200 mCi) every 4-6 months during the first two years and then at longer intervals or with an activity based on a dosimetric approach. Two dosimetric approaches have been described: quantitative tumor dosimetry estimates the activity needed to deliver an effective radiation dose to the metastases, based on the initial RAI tumor concentration (the ratio between initial RAI uptake and tumor volume) and the effective half-life of RAI in the tumor tissue: studies have suggested that radiation doses to the tumor $>80 \mathrm{~Gy}$ will provide best effects, whereas doses <35 Gy will induce minimal or no effect (Maxon et al. 1983, Sgouros et al. 2004); the other approach is blood dosimetry that determines the largest activity that can be administered while keeping bone marrow exposure $\leq 2$ Gy (Deandreis et al. 2017). Activities based on weight (37-74 MBq/kg body weight) are given to children (Rivkees et al. 2011). Between 131I treatments, levothyroxine is used to maintain a low serum TSH level. In the few available retrospective studies in patients with distant metastases, there is no evidence that dosimetry may increase the efficacy of RAI treatment over empiric activities: in one study, the outcome of patients with distant metastases (tumor response and overall survival) was similar after treatment with empiric activities or with activities based on dosimetry (Klubo-Gwiezdzinska et al. 2011); in another study, the outcome (overall survival) was similar after treatment with empiric activities of $3700 \mathrm{MBq}$ and with higher activities determined with blood dosimetry (Deandreis et al. 2017).

There are several reasons why RAI may not be effective, even in the presence of RAI uptake (Schlumberger et al. 2007a). Radiation dose is usually lower in tumor thyroid tissue than in normal thyroid tissue because the uptake is lower and the effective half-life is shorter. Tumor dosimetry may be used to deliver radiation doses to the tumor that are high enough to be effective, but this may be not achievable for low tumor uptake or short effective half-life. Furthermore, the distribution of the radiation dose is heterogeneous among patients, and in a given patient, among functioning metastases as shown by positron emission tomography (PET) scanning with ${ }^{124} \mathrm{I}$ and also within a given metastasis (Sgouros et al. 2004). Heterogeneity in the RAI uptake is also observed at the cellular level and because of the short path of the beta emitted by ${ }^{131} \mathrm{I}$, this will result in a heterogeneous dose distribution despite significant mean uptake on whole body scan (WBS) (Schlumberger et al. 2007a). These observations may explain why higher activities may not improve the outcome. 
For RAI treatment to be effective, appropriate levels of TSH stimulation and absence of iodine contamination are essential. Excess iodine is eliminated one month after administration of an iodinated contrast CT scan (Padovani et al. 2012). Prolonged withdrawal of thyroid hormone treatment with a serum TSH above an arbitrary level of 30IU/L usually induces higher uptake in neoplastic foci than injections of recombinant human TSH (rhTSH) and is the preferred method of TSH stimulation in patients with known metastatic disease (Potzi et al. 2006, Plyku et al. 2017). Similar short-term survival rates were observed in patients with distant metastases after ${ }^{131}{ }^{13}$ treatment prepared with either withdrawal or rhTSH (Tala et al. 2011), but no comparative data are available on long-term outcome. RhTSH-mediated therapy may be indicated in selected metastatic patients with underlying comorbidities making iatrogenic hypothyroidism potentially risky and in patients with pituitary disease who are unable to raise their serum TSH (Schlumberger et al. 2007b).

Fluoro-deoxyglucose (FDG) PET is performed in patients with distant metastases for several reasons: it may reveal metastases without RAI uptake that are not visible on RAI-WBS, including in bones; RAI treatment is less effective in patients with metastatic uptake of FDG and FDG uptake indicates more aggressive disease (Robbins et al. 2006, Rivera et al. 2008, Deandreis et al. 2011a, Nascimento et al. 2015). However, some tumor responses have been observed in patients with both RAI and FDG uptake in their metastases and the decision not to treat with RAI should not be based only on the presence or intensity of FDG uptake; furthermore, in a given patient, metastases with the highest FDG uptake do not have a more aggressive behavior than the other metastases (Terroir et al. 2017).

Favorable responses to RAI treatment are characterized by parallel decreases in tumor volume on anatomical imaging and in functional parameters (131I uptake in metastases on post-therapy WBS and serum thyroglobulin (Tg) level). Disappearance of imaging abnormalities have been obtained overall in about $45 \%$ of the patients with distant metastases showing initial avidity for ${ }^{131}$ I with a median cumulative activity of $7400 \mathrm{MBq}$ and almost all complete responses being achieved with a cumulative activity of 22,000 MBq (Durante et al. 2006). Complete responses are more frequently achieved in younger patients, in those with small pulmonary metastases, who had a well-differentiated cancer and who have no or low FDG uptake (Durante et al. 2006, Robbins et al. 2006, Rivera et al. 2008, Deandreis et al. 2011a). Relapse after complete response occurred in less than $10 \%$ of patients, even though serum Tg levels were persistently detectable in some patients (Durante et al. 2006). In these patients, overall survival after the discovery of distant metastases is favorable. When the tumor mass is considered, the location of the distant metastases, be it in the lungs or bone, has no independent prognostic influence. Small radio-avid bone metastases with no structural abnormalities respond to therapy (Robenshtok et al. 2014) and the poor prognosis of most patients with bone metastases is linked to the large size of their lesions (Ruegemer et al. 1988, Casara et al. 1993, Bernier et al. 2001, Durante et al. 2006).

Patients with advanced disease that does not respond to ${ }^{131}$ I treatment (refractory disease) have a median life expectancy of 3-6 years (Durante et al. 2006). This occurs more frequently in older patients, in those with large metastases or with poorly differentiated thyroid cancer and in those with FDG uptake (Durante et al. 2006, Robbins et al. 2006, Rivera et al. 2008, Deandreis et al. 2011a). Fortunately, major advances have been achieved in recent years for the treatment of these rare patients.

\section{Definition of radioiodine-refractory thyroid cancer}

Radioiodine-refractory thyroid cancer occurs in the twothirds of distant metastases in whom a complete response is not achieved with radioiodine (Durante et al. 2006). It is an uncommon condition, with an estimated incidence of 4-5 cases per million population (around 250 patients per year in France) (Schlumberger et al. 2014).

It is important to recognize at which point RAI treatment is no longer beneficial for DTC patients, in order to avoid unnecessary treatments that may lead to adverse events (AEs) and also that may delay the initiation of systemic treatment to a point when this treatment may be less effective. Most patients with RAI refractory differentiated thyroid carcinoma fall into four categories (Table 1): (a) Patients with metastatic disease that does not take-up RAI at the time of the initial treatment. This group includes patients with structurally evident disease with no RAI uptake on a diagnostic WBS, because in such patients, the administration of a therapeutic activity of ${ }^{131} \mathrm{I}$, even in the presence of uptake on post-therapy scans, will not induce benefits (Sabra et al. 2012). (b) Patients whose tumors lose the ability to take-up ${ }^{131}$ I after previous evidence of uptake. This may be due to the heterogeneous dose distribution in the thyroid tumor tissue that leads to the eradication of differentiated cells able to take-up ${ }^{131}$ I, but not of less differentiated cells that do not take-up ${ }^{131}$. (c) Patients with ${ }^{131}$ I uptake retained in some lesions but not 
Table 1 Definition of radioactive iodine (RAI) refractory disease and criteria for initiating TKI treatment.

Definition of RAI refractory disease patient with a RAI refractory disease

Other criteria for initiating a TKI treatment in a patient with a RAl refractory disease
1. Absence of initial RAl uptake in metastases

2. Absence of RAI uptake in metastases after treatment with RAI

3. Presence of RAI uptake in some metastases, but absence in others

4. Progression despite RAl uptake in all metastases

5. Controversial: high FDG uptake, aggressive histology, persistence of disease after several RAI treatment courses

1. Large tumor burden: tumors greater than $1-2 \mathrm{~cm}$ in size

2. RECIST progressive disease in $<12$ months

3. Symptomatic disease and risk of local complications

1. Good performance status and acceptable life expectancy

2. Absence of comorbidities or contraindications

3. Good compliance to treatment and to follow-up procedures in others. This is frequently seen in patients with multiple large metastases (Sgouros et al. 2004), and progression is likely to occur in metastases without ${ }^{131}$ I uptake (Robbins et al. 2006, Rivera et al. 2008, Deandreis et al. 2011a). (d) Patients with metastatic disease that progresses despite significant RAI uptake in their metastases and following courses of adequate radioiodine treatment (Vaisman et al. 2011). In any of these patients with refractory disease, further ${ }^{131}$ I treatment will not provide benefits and should be abandoned.

Less clear is the situation for patients with poorly differentiated thyroid cancer, with high uptake of FDG on PET or with persistent visible RAI uptake in all or most lesions which are not cured despite several treatment courses but whose disease does not progress. For these patients, long-term stabilization may be achieved, but the probability of obtaining a cure with further 131I treatment is low (Durante et al. 2006) and side effects may increase, including the occurrence of secondary cancers and leukemias (Rubino et al. 2003). Also, the outcome of patients who achieved a complete response with a cumulative activity higher than $22,000 \mathrm{MBq}$ was not better than that of patients who never achieved a complete response (Thies et al. 2014). The decision to continue ${ }^{131} \mathrm{I}$ treatment in such patients (particularly after receiving more than $22,000 \mathrm{MBq}$ of ${ }^{131} \mathrm{I}$ ) is generally based on their response to previous treatment courses, persistence of a significant level of ${ }^{131}$ I uptake on the previous post-therapy WBS, low FDG uptake in tumor foci and absence of side effects (Durante et al. 2006).

Some patients may experience dissociated response to ${ }^{131}$ I treatment, with a tumor response in some lesions and progression in other lesions; in such patients, focal treatment modalities may be applied on progressive lesions and other ${ }^{131}$ I treatment courses may be given according to the above-mentioned criteria. When the thyroid gland has not been removed, RAI treatment is usually not administered and RAI uptake status cannot be assessed. These patients are usually managed as iodinerefractory patients.

A potential way of treating RAI refractory patients is to restore the ability of radioiodine uptake in tumor cells, and then to treat with radioiodine. In fact, in papillary thyroid cancer, dedifferentiation is associated with the activation of the MAP kinase pathway that is more pronounced in case of $B R A F$ V600E mutation. This dedifferentiated phenotype is characterized by an impaired iodide metabolism, a higher FDG uptake and RAI refractory and more aggressive disease (Durante et al. 2007, Cancer Genome Atlas Research Network 2014, Nagarajah et al. 2015, Fagin \& Wells 2016). This may act through the expression of TGF-beta that in turn stimulates, through the smad3 pathway, the production of reactive oxygen species by NOX4. This results in a decreased expression of thyroid functional proteins, including NIS and TPO that is likely to be due to epigenetic changes and is reversible (Azouzi et al. 2017). In a pilot study on 20 patients with metastatic differentiated thyroid carcinoma who had no significant RAI uptake in their metastases, lesional dosimetry with 124I PET imaging was performed following rhTSH stimulation after 4 weeks of treatment with the MEK inhibitor, selumetinib. Twelve patients demonstrated increased tumoral ${ }^{124}$ I uptake, and 8 of these 12 patients achieved sufficient iodine reuptake to warrant treatment with ${ }^{131} \mathrm{I}$ : 5 achieved Response Evaluation Criteria in Solid Tumor (RECIST) partial responses (PR) and 3 had a stable disease. Of the 20 patients, 9 patients had tumors with the V600E BRAF mutation and 5 patients had tumors with NRAS mutations at codon 61. Interestingly, of the 8 patients with a major increased ${ }^{124}$ I uptake, 5 were found to have NRAS mutations and one a BRAF mutation (Ho et al. 2013). In another trial on 10 patients with a $B R A F$ mutation, the BRAF inhibitor dabrafenib induced the reappearance of RAI uptake in 6 who were treated with radioiodine and 2 patients achieved a PR (Rothenberg et al. 2015). This approach may be relevant in patients 
with small distant metastases with a slow progression rate and with a baseline radioiodine uptake that is undetectable or too low to allow significant radiation doses to be delivered. In patients with baseline RAI uptake in their metastases, this therapeutic intervention may also lead to the delivery of higher radiation doses with a more homogeneous radiation dose distribution in tumor foci.

\section{Treatment of refractory thyroid cancer}

In patients with refractory thyroid cancer, ${ }^{131}$ I treatment is abandoned, levothyroxine treatment is administered to maintain a low serum TSH level (unless contraindications are present) and focal treatment on metastases is performed whenever needed, as well as bone-directed therapies in patients with bone metastases. Surveillance includes an FDG-PET or a CT scan with contrast of the head, neck, chest, abdomen, and pelvis, at an interval of 3-12 months that is dictated by tumor burden, tumor location and by the pace of prior disease progression and of serum $\mathrm{Tg}$ doubling time (Miyauchi et al. 2011). Most patients with refractory advanced disease have an aggressive course, but the disease can be asymptomatically stable for long periods of time, in particular in young patients with small lung metastases from a well-differentiated carcinoma who are maintained on levothyroxine treatment, because in such patients, the benefits of novel therapies may be largely outweighed by drug toxicities.

The decision to initiate systemic treatment in patients with radioiodine-refractory disease should be taken by a multidisciplinary board and is based on several parameters, including tumor burden, disease progression, location of tumor foci with a high risk of local complications, presence of symptoms and comorbidities (Table 1). Progression rate can be estimated by the doubling time of serum Tg (Miyauchi et al. 2011), but should always be confirmed by imaging using RECIST (Eisenhauer et al. 2009, Schlumberger et al. 2014, Haugen et al. 2016, Brose et al. 2017a, Tuttle et al. 2017). RECIST progression is defined by a $20 \%$ increase of the sum of the diameters of target lesions that corresponds to a doubling in tumor volume.

Indeed, patients with multiple lesions $>1-2 \mathrm{~cm}$ and with documented progression within less than 12 months are considered for systemic treatment, that should be initiated at an earlier stage in case of rapid progression. On the contrary, asymptomatic patients with few and/or small metastatic lesions $<1 \mathrm{~cm}$ and those with no evidence of progression are considered for no treatment but for follow-up every 3-12 months. In patients with few metastases or with a predominant metastasis, or with symptoms, focal treatment modalities may control these tumor foci and may allow postponing initiation of systemic treatment. Some patients with large tumor burden for whom there are no data on progression may be considered for systemic treatment when there is a high risk of local complications (Eisenhauer et al. 2009, Schlumberger et al. 2014, Haugen et al. 2016, Brose et al. 2017a, Tuttle et al. 2017).

\section{Cytotoxic chemotherapy}

Cytotoxic chemotherapies provided low response rates (from $0 \%$ to $22 \%$ with the most frequently used agent, doxorubicin at a dose of $60 \mathrm{mg} / \mathrm{m}^{2}$ every 3-4 weeks) and toxicity was high (Sherman 2010). However, cytotoxic chemotherapy with recent drugs such as gemcitabine, oxaliplatin or taxane may be used since they were effective in anecdotal patients (Crouzeix et al. 2012, Spano et al. 2012).

\section{Molecular-targeted therapy}

In most DTC patients, an initiating carcinogenic event can be found and molecular-targeted therapy could be given with a scientific rationale (Phay \& Ringel 2013, Cancer Genome Atlas Research Network 2014, Fagin \& Wells 2016). The MAP kinase pathway is activated in the majority of papillary thyroid cancers, mainly by either gene rearrangements (RET-PTC and NTRK) or point mutations of the RAS and BRAF genes. Point mutations of the RAS genes are frequently found in follicular and poorly differentiated carcinomas. Additional genetic abnormalities may be found in poorly differentiated thyroid carcinomas. Angiogenesis is activated in thyroid cancers (Bunone et al. 1999, Durante et al. 2011), by activation of the VEGFR pathway and other pathways may also be activated, including the FGFR and PDGFR pathways (Voce et al. 2011).

Up to now, most drugs used in refractory thyroid cancers are anti-angiogenic and some also target kinases in the MAP kinase pathway. With these agents, PR were observed (Cohen et al. 2008, Gupta-Abramson et al. 2008, Sherman et al. 2008, Hoftijzer et al. 2009, Kloos et al. 2009, Bible et al. 2010, Carr et al. 2010, Ahmed et al. 2011, Capdevila et al. 2012, Leboulleux et al. 2012, Brose et al. 2014, Cabanillas et al. 2014, 2015, 2017, Locati et al. 2014, Schlumberger et al. 2015, Bastholt et al. 2016) and even more importantly median progression-free survival (PFS) was prolonged in phase III trials when compared with 
Table 2 Efficacy of anti-angiogenic in RAI refractory thyroid cancer.

\begin{tabular}{l} 
Axitinib \\
Cohen \\
Locati \\
Cabozantinib \\
Cabanillas \\
Lenvatinib \\
Select (phase III vs placebo) \\
Schlumberger \\
Motesanib \\
Sherman \\
Pazopanib \\
Bible \\
Sorafenib \\
Decision (phase III vs \\
placebo) Brose \\
Sunitinib \\
Cohen \\
Carr \\
Vandetanib \\
Zacthyf (phase II vs placebo) \\
Leboulleux \\
Verify. Bastholt \\
\hline
\end{tabular}

\begin{tabular}{|c|c|}
\hline VEGFR & Other targets \\
\hline+ & RET, PDGFR, KIT \\
\hline+ & RET, C-MET \\
\hline+ & RET, FGFR, PDGFR,C-KIT \\
\hline+ & PDGFR, KIT, RET \\
\hline+ & PDGFR, KIT \\
\hline+ & RET, BRAF, PDGFR, KIT \\
\hline+ & RET, PDGFR, KIT \\
\hline+ & RET, EGFR \\
\hline
\end{tabular}

\begin{tabular}{|c|c|c|}
\hline$n$ & PR (\%) & SD >6 month $(\%)$ \\
\hline 45 & 31 & 38 \\
\hline 45 & 38 & 29 \\
\hline 15 & 53 & 40 \\
\hline 392 & 65 & \\
\hline 93 & 14 & 33 \\
\hline 37 & 49 & \\
\hline 417 & 12 & \\
\hline 31 & 13 & 68 \\
\hline 29 & 28 & 46 \\
\hline $\begin{array}{l}145 \\
238\end{array}$ & 0 & \\
\hline
\end{tabular}

Median PFS vs placebo Drug (months) Placebo (months)

PFS, progression-free survival; PR, partial response; SD, stable disease.

placebo (Table 2). The lack of demonstrated improvement in overall survival might have been related to the crossover design of the studies with treatment in an open phase in case of progression in the placebo arm and the long survival of some patients after their participation to the trial during which other treatment modalities were used. Three medications have been evaluated in randomized phase III trials vs placebo.

ZACTHYF phase II randomized trial with vandetanib $(300 \mathrm{mg} /$ day) vs placebo on 145 patients with RAI refractory locally advanced or metastatic DTC that had progressed within the past 14 months produced a significant prolongation of the median PFS (hazard ratio (HR): $0.63, P=0.008$; median: 11.1 vs 5.9 months, respectively) and an objective partial response rate of $8 \%$ (Leboulleux et al. 2012). The subsequent VERIFY phase III trial with vandetanib vs placebo on 238 patients produced a non-significant improvement of median PFS (HR: 0.75; $P=0.08$; median PFS: 10.0 vs 5.7 months, respectively) (Bastholt et al. 2016).

DECISION phase III trial was performed on 417 naïve patients with RAI refractory locally advanced or metastatic DTC that had progressed within the past 14 months (Brose et al. 2014). Patients were randomized 1:1 either to sorafenib ( $400 \mathrm{mg}$ administered orally twicedaily) or placebo. Sorafenib treatment significantly improved median PFS compared with placebo (HR:
0.587; 95\% CI: 0.454-0.758; $P<0.0001$; median PFS: 10.8 vs 5.8 months, respectively). The improvement in PFS was seen in all clinical subgroups. The partial response rate was $12 \%$ and stable disease for 6 months or longer was achieved in $41.8 \%$ of patients. The safety profile of sorafenib was as expected, but with a higher incidence of AEs than in patients with other cancer types. Most AEs were grade 1 and 2, the most common being hand-foot skin reaction (76\%), diarrhea (69\%), alopecia (67\%) and rash/desquamation (50\%). Toxicities led to dose reduction in $64 \%$ of patients and to drug withdrawal in $19 \%$.

SELECT phase III trial was performed on 392 patients with RAI refractory locally advanced or metastatic DTC that had progressed within the past 13 months; progression was confirmed by an independent radiological review (Schlumberger et al. 2015). Patients were randomized 2:1 either to lenvatinib $(24 \mathrm{mg} /$ day) or placebo. Lenvatinib treatment significantly improved median PFS compared with placebo (HR: 0.21 ; 99\% CI: $0.14-0.31, P<0.001$; median PFS: 18.3 vs 3.6 months, respectively) and the objective response rate was $65 \%$ with complete responses in $2 \%$. The improvement in PFS was seen in all clinical subgroups, including in the $20 \%$ of patients who had received prior VEGF-targeted therapy. Treatmentrelated adverse events were reported in all patients in the lenvatinib group, including hypertension (68\%), fatigue (64\%), diarrhea (59\%) and decreased appetite 
(50\%). Proteinuria occurred in 32\% and thromboembolic events in $11 \%$. Toxicities led to dose reduction in $68 \%$ of the patients, to dose interruption in $82 \%$ and to drug withdrawal in $14 \%$ of patients. Investigators attributed 6 fatalities $(2 \%)$ to the use of lenvatinib (pulmonary embolism in one, hemorrhagic stroke in one and general health deterioration in the other 4). In a subsequent analysis, a rapid decline in tumor size by $25 \%$ was reported at the 8-week evaluation; the duration of PFS was related to the magnitude of the initial tumor size decrease, and a multivariate analysis identified two predictive indicators for the decrease in size, performance Eastern Cooperative Oncology Group (ECOG) status of 0 or 1 and small size of metastases (Robinson et al. 2016). In the real-life experience in France on 75 patients, the ORR was 31\%, but when excluding patients with poor performance status, those who had been heavily pretreated and those with very large metastases, results were similar to those of SELECT (Berdelou et al. 2017). There was no benefit of lenvatinib treatment in the overall survival rate in SELECT patients, but in a subgroup analysis, a significant benefit was observed in patients aged above 65 years, related to the beneficial effects of lenvatinib in patients with more aggressive disease (Brose et al. 2017b).

In conclusion, results of DECISION and SELECT were positive and led to the approval of sorafenib and lenvatinib for advanced, refractory and progressive DTC by FDA and by EMA. Both vandetanib and sorafenib improved median PFS by 5 months over placebo, but with few PR and are mainly considered as cytostatic. Despite the absence of direct comparison, lenvatinib seems more effective: it improves median PFS by almost 15 months over placebo and induces a response rate as high as 65\%, with few complete responses. Both in SELECT trial and in real life, maximal benefits were achieved in patients with an ECOG performance status of $0-1$, who were not heavily pretreated and who had a limited tumor burden. There was no unexpected toxicity, but toxicity was frequent and should be managed by experienced teams. Because the initial dosage of lenvatinib ( $24 \mathrm{mg} /$ day) had to be reduced in two-thirds of patients after a median time of 3 months (Schlumberger et al. 2015), an ongoing randomized trial is comparing efficacy and safety of initial daily doses of $18 \mathrm{mg}$ vs $24 \mathrm{mg}$ (NCT02702388). Also, it may be safe to initiate lenvatinib treatment at a lower dose in elderly patients and in those at risk of toxicities.

Predictive biomarkers are aimed to allow a better selection of patients for any treatment modality and also an early assessment of the tumor response to the drug. Oncogenic events that have been described in thyroid cancers have been studied in several trials. In DECISION and in SELECT trials, PFS was improved in all biomarker subgroups, irrespective of BRAF and RAS mutation status (Brose et al. 2014, Schlumberger et al. 2015). In patients treated with motesanib, decrease from baseline in serum placental growth factor after 1 week of treatment correlated with best tumor response, and a decrease in soluble VEGF receptor 2 after 3 weeks of treatment separated between responders and non-responders. Lower baseline VEGF levels were associated with longer PFS (Bass et al. 2010). In SELECT trial, low baseline levels of angiopoietin-2 were associated to maximum tumor shrinkage, overall response rate and longer PFS; fibroblast growth factor 23 (FGF23) upregulation after 15 days of treatment was associated with longer PFS (Tahara et al. 2017). These studies have shown the promise of using biomarkers in predicting drug efficacy, which needs to be refined before they can be used in clinical practice in individual patients.

There are few available data on the use of FDG-PET for an early prediction of response to TKI treatment: comparison of FDG uptake at 1-2 weeks with baseline FDG uptake has produced inconsistent results and the interest of repeated FDG-PET/CT in the management of DTC patients during treatment is still unclear. During the treatment with sunitinib, a decrease in FDG uptake was associated with subsequent tumor response and an increase with subsequent tumor progression (Carr et al. 2010). However, in ZACTHYF, no such relationship was observed (Leboulleux et al. 2012).

\section{Drugs directed against other targets}

Mutation screening should be performed on a routine basis in RAI refractory patients, because the presence of a driver mutation may lead to the use of a specific inhibitor. Many data have been obtained on thyroid tumor tissues that were resected long before treatment and analysis of the metastatic tumor tissue at the time of treatment would probably be more informative (Ricarte-Filho et al. 2009).

The presence of BRAF mutation was an inclusion criterion in phase 2 trials with a BRAF inhibitor, either vemurafenib or dabrafenib (Dadu et al. 2015, Falchook et al. 2015, Brose et al. 2016) and positive results were observed, and these results may be improved by a combination with a MEK inhibitor. Mutation in $A L K$ (anaplastic lymphoma kinase) gene has been reported in few patients with refractory DTC and can be the target of an ALK inhibitor (Kelly et al. 2014). Other pathways, such as the PI3K-AKT pathway (Ringel et al. 2001, Xing 2010) 
that is activated in follicular and poorly differentiated carcinoma may also be a target for treatment.

Immunological intervention may use two directions. One is guided by the increased number of tumorassociated macrophages (TAMs) in aggressive tumors that culminates in anaplastic thyroid cancer (Ryder et al. 2008, Caillou et al. 2011). In transgenic mice, depletion of TAMs through inhibition of the colony-stimulating factor 1 (CSF1) pathway that attracts TAMs into the tumor impairs tumor progression (Ryder et al. 2013). Another one is the fact that some tumors evade immunosurveillance, possibly through changes over time of their immunological profile (Ott et al. 2013). In a phase II trial, pembrolizumab, a PD-1 inhibitor induced 2 PR in 22 treated patients (Mehnert et al. 2016). Combination therapy with an anti-angiogenic medication may permit to obtain high rates of complete responses with longer durations of responses.

\section{Clinical practice and future developments}

Abandon of RAI therapy, modalities of follow-up, initiation of TKI treatment and its termination are best decided in the frame of a multidisciplinary team with the participation of nuclear medicine specialists, endocrinologists and medical oncologists. Indeed, the participation of other specialists in surgery, diagnostic imaging, interventional radiology, radiation oncology and in other fields may enrich the decisions. This permits to deliver a unified message regarding treatment options, empower patients with well-informed choices and increase confidence through consensus. Once the decision to treat with TKI has been taken, treatment and follow-up are best realized with a co-management by the treating physician and a medical oncologist.

\section{Initiation of systemic treatment}

One main challenge is to properly select patients for systemic therapy. As all these medications can cause a significant decrease in quality of life (QoL) and adverse effects that may be life threatening, patients with distant metastases that are over $1-2 \mathrm{~cm}$ in size and that progress are candidates for systemic treatment (Schlumberger et al. 2014, Haugen et al. 2016). Dyspnea, painful bone lesion, symptomatic brain metastases, as well as lesions with high risk of complication should first be submitted to focal therapy. Also, symptomatic treatment modalities are always warranted, as well as bisphosphonates or antiRANK ligand antibody in patients with bone metastases. The presence of tumor foci in certain location may be an indication to initiate treatment, even in patients with no demonstrated progression: treatment should be initiated before the occurrence of tumor involvement of the trachea or esophagus and before encasement of great vessels that may contraindicate the use of TKI with respect of the risk of bleeding or fistula (Blevins et al. 2014, Lamartina et al. 2016). External beam radiation therapy on metastases may be performed during TKI treatment, and there is no evidence that irradiation of brain metastases before the initiation of TKI treatment may decrease the risk of bleeding (Tallet et al. 2017).

Before initiation, evaluation includes assessment of the patient's performance status. Tolerance and efficacy are lower in patients with a poor performance status (e.g. ECOG 2 or more). Symptomatic treatments may be needed to improve performance status before initiation of TKI treatment. The absence of comorbidities or contraindications should also be assessed, including cardiovascular history, control of blood pressure, absence of hematological, renal and hepatic abnormalities that may contraindicate any TKI treatment or may indicate treatment initiation at a lower dosage (Table 3).

Finally, due to the duration of treatment, the potential for toxicities, and the need for regular monitoring, the patients must be aware that the follow-up will be close and may be prolonged for years.

In countries where several drugs are labeled, the most effective drug should be used as first-line treatment, as in other cancer types. Furthermore, it has been shown that lenvatinib is more effective in patients with a general good ECOG performance status who have not been heavily pretreated and in whom the tumor burden is limited. Also, only a fraction of these patients will receive a second-line treatment. Lenvatinib that appeared to be the most effective drug is thus used as first-line treatment in the absence of contraindication. Treatment should be initiated when tumor burden is still limited, preferably before the appearance of symptoms and at a stage when large vessels and the tracheoesophageal tracts are not involved by the disease (Blevins et al. 2014, Lamartina et al. 2016). Trial consideration should be given to all patients, even in countries where a drug is currently approved.

In those at risk of toxicities, the initial dose of lenvatinib may be reduced to 18 or even $14 \mathrm{mg}$ /day. In patients with a poor tolerance and as an alternative to dose reduction, an intermittent drug administration may be offered when a tumor response has been achieved, and this may improve the QoL and allows patients to program their social activities during drug holidays. 
Table 3 Contraindications or factors discouraging TKI treatment.

Contraindications
Intestinal or liver disease
High risk of bleeding and/or fistula

High cardiovascular risk

Hypertension

Prolonged QTc interval

Renal

Cachexia, poor nutrition, sarcopenia

Untreated brain metastases

Concomitant medication that induce or inhibit CYP3A4

\section{Comments}

Active or recent diverticulitis, inflammatory bowel disease, recent bowel resection Laboratory: AST-ALT > 5 times the upper limit of normal range; increased bilirubin level Recent gastrointestinal hemorrhage or hemoptysis

Coagulopathy or anticoagulant treatment

Tumor involvement of the trachea-bronchus and of the pharyngo-esophagus tracts Encasement of great vessels

Unstable angina, myocardial infarction or stroke within 6 months prior TKI initiation, left ventricular dysfunction

Avoid TKI in patients with recent thromboembolic events in the preceding 6-12 months. Withhold treatment upon occurrence and consider permanent discontinuation for arterial thrombosis

Use long-term low-molecular-weight heparin

Uncontrolled hypertension may occur during the first days of treatment with lenvatinib. Initiate antihypertensive treatment if blood pressure is $>14 / 9$. Initiate TKI treatment only when blood pressure is normalized

QTC $>450$ ms at baseline

History of ventricular and bradyarrhythmias

Control blood levels of calcium, potassium, magnesium and TSH

Avoid the use of other drugs that may prolong QT

Minor QTc prolongation during sorafenib or lenvatinib treatment

Creatinine clearance $<60 \mathrm{~mL} / \mathrm{min}$

Proteinuria $>1 \mathrm{~g} / 24 \mathrm{~h}$

Symptomatic care should improve performance status

Provide dietary recommendations and encourage physical exercise

Controversial risk of bleeding. No evidence that radiation therapy of brain metastases before initiation of TKI treatment may decrease the risk of bleeding

Avoid or substitute for another drug. If cannot be eliminated, consider a dose reduction in the TKI

\section{Control of safety and of efficacy}

AEs are frequently under-reported (from $13 \%$ up to $50 \%$ ) by care providers (Di Maio et al. 2015). They occurred more frequently in patients aged older than 65 years (Brose et al. 2017b). Patients should be encouraged to declare their AEs as soon as they appear because their treatment at an early stage is more effective and may improve compliance. Pharmacokinetics may permit to avoid these AEs, by guiding the treatment dose according to blood levels. Safety may be improved by treating patients with an ECOG performance status of $0-1$, by searching for contraindications and correcting major defects, including by treating high blood pressure, before treatment initiation.

Education should be provided to each patient and to care providers. It is highly recommended after initiation of treatment to follow-up patients at 2-week intervals for the first 2-3 months and then once a month in order to proactively manage AEs, in accordance with the tolerance of each individual patient.

The most common AEs and their management are presented in Table 4. Fortunately less common, serious AEs are hypertension, arterial and venous thrombotic events, bleeding, gastrointestinal fistula and perforation, acute myocardial infarction, heart failure, cytopenias, hepatotoxicity, renal failure and reversible posterior leukoencephalopathy syndrome.

With any of these anti-angiogenic medications, the dose of levothyroxine treatment had to be increased in the majority of patients, and an increased need in calcium and vitamin D analog may also occur, particularly in patients treated for post-operative hypoparathyroidism.

Efficacy is assessed every 8-12 weeks with imaging. Tumor responses were observed in a fraction of patients that was more important with some agents (lenvatinib, pazopanib, cabozantinib) but even with these agents, most responses were partial. Long-term stabilization of the disease that was demonstrated to be progressive before the initiation of treatment may indeed be beneficial.

\section{Termination of treatment}

The duration of treatment is not yet validated and for this reason, treatmentis usually given aslong as toxicities remain manageable and there is evidence of benefits. In patients with a dissociated response with only a few progressive metastases that may be controlled by local treatment modalities, systemic treatment may be maintained. Rapid 
Table 4 Principal side effects of tyrosine kinase inhibitors and their management.

\begin{tabular}{|c|c|c|}
\hline Adverse events & Frequency (any grade) & Frequency (grade $\geq 3$ ) \\
\hline Hypertension & $\begin{array}{l}\text { Lenvatinib } 69 \% \\
\text { Sorafenib } 41 \% \\
\text { Sunitinib } 36 \% \\
\text { Pazopanib } 48 \% \\
\text { Vandetanib } 32 \%\end{array}$ & $\begin{array}{l}\text { Lenvatinib } 42 \% \\
\text { Sorafenib } 10 \% \\
\text { Sunitinib } 13 \% \\
\text { Pazopanib 3\% }\end{array}$ \\
\hline
\end{tabular}

\section{Management}

Cardiac assessment with left ventricular fraction measurement before TKI start and every 3 months during treatment

Educate patients at frequent blood pressure surveillance and self-measurement

Target blood pressure $\leq 140 / 90 \mathrm{mmHg}$ (lower in case of overt proteinuria)

1st-line anti-hypertensive medications

Angiotensin-converting enzyme inhibitors

Angiotensin II receptor blockers

Non-dihydropyridine calcium channel blockers

If diuretics are used, monitor electrolytes and avoid dehydration

Diarrhea

Lenvatinib 58\%

Pazopanib 48\%

Selumetinib $45 \%$

Sorafenib $68.6 \%$

Vandetanib $74 \%$

Vemurafenib $46 \%$

Fatigue

Lenvatinib 59\%

Pazopanib 78\%

Selumetinib $80 \%$

Sorafenib $50 \%$

Vandetanib 49\%

Vemurafenib $69 \%$

Nausea

Lenvatinib $41 \%$

Pazopanib 73\%

Selumetinib $40 \%$

Sorafenib $21 \%$

Vandetanib 25\%

Vemurafenib $46 \%$

Stomatitis

Lenvatinib 36\%

Selumetinib 35\%

Sorafenib 23\%

Weight loss

Lenvatinib $46 \%$ Sorafenib $47 \%$

Proteinuria

Lenvatinib 31\%

Pazopanib 37\%

Sunitinib 22\%

Vemurafenib 23\%

Increased TSH

Lenvatinib $62 \%$

Sorafenib 33\%

Skin rash
Lenvatinib $16 \%$

Selumetinib $70 \%$

Sorafenib 502\%

Vandetanib 74\%

Vemurafenib $73 \%$
Lenvatinib 8\%

Sorafenib 5.3\%

Lenvatinib $10 \%$

Vandetanib 9\%

Sorafenib 6\%

Lenvatinib $2.3 \%$

Lenvatinib $4 \%$

Sorafenib $<1 \%$

Lenvatinib $10 \%$

Sorafenib 6\%

Lenvatinib 10\%

Lenvatinib $<1 \%$

Sorafenib 5\%
Exclude other causes of diarrhea

Diet adjustment (low fiber food, avoid high fat and spicy foods, alcohol, caffeine and carbonated drinks)

Search for steatorrhea (fat $>6 \mathrm{~g} / 24 \mathrm{~h}$ and low fecal elastase) and if present administer pancreatic extracts and vitamin D

Loperamide and codein

Probiotics may be beneficial

Assessment with validated questionnaires (e.g. EORTC QLQ C30 or Brief Fatigue Inventory)

Regular physical activity

Take pills in the evening

Monitor other causes of fatigue (anemia, depression, electrolytes and calcium disturbances)

Metoclopramide

Ondansetron, Granisetron (consider risk of QT prolongation)

Oral hygiene and frequent mouthwash with water and baking soda

Topic analgesics alone or in combination (lidocaine $2 \%$, diphenhydramine, bismuth subsalicylate, aluminum or magnesium hydroxide)

Nutritional assessment at baseline and then periodically Oral nutritional supplements

Enteral nutritional supplements if needed

Baseline and periodic assessment (urine stick and if $>1+$ $24 \mathrm{~h}$ proteinuria)

Angiotensine-converting enzyme inhibitors

Dose reduction

Discontinuation in case of nephrotic syndrome (nephrologic advice in case of proteinuria $>3 \mathrm{~g} / 24 \mathrm{~h}$ )

Periodic TSH testing and levothyroxine dose adjustment

Sunscreen with very high sun protection factor $(\geq 50)$ in case of photosensitivation

Doxycycline or Minocycline $100 \mathrm{mg}$ bid in case of folliculitis (doxycycline might increase photo sensitivation)

Use perfume free soap and loose natural fabric clothing Avoid hot and cold water 
Table 4 Continued

$\begin{array}{ll}\text { Adverse events } & \text { Frequency (any grade) } \\ \text { Hand and foot } & \text { Lenvatinib } 32 \% \\ \text { syndrome } & \text { Sorafenib } 76 \% \\ & \text { Pazopanib } 8.6 \%\end{array}$

Frequency (grade $\geq 3$ )

Lenvatinib 3.4\% Sorafenib $20 \%$

\begin{tabular}{|c|c|c|}
\hline Skin tumors & $\begin{array}{l}\text { Sorafenib } \\
\text { Vemurafenib (4-46\%) }\end{array}$ & \\
\hline Arthralgias and & Lenvatinib $18 \%$ & Lenvatinib $2 \%$ \\
\hline myalgias & Pazopanib 9\% & Sorafenib 9\% \\
\hline & Sorafenib 9\% & \\
\hline & Sunitinib $43 \%$ & \\
\hline & Vemurafenib 59\% & \\
\hline $\begin{array}{l}\text { Venous or arterial } \\
\text { thrombosis }\end{array}$ & & Lenvatinib 3\% \\
\hline Hemorrhage & Pazopanib 13\% & Lenvatinib $1 \%$ \\
\hline & Sorafenib 15\% & Pazopanib 2\% \\
\hline & Sunitinib 30\% & Sorafenib 3\% \\
\hline & & Sunitinib 3\% \\
\hline
\end{tabular}

QTc prolongation Vandetanib 23\%

\section{Management}

Prevention: Removal of hyperkeratotic lesions from hands and feet

Avoid traumatism (also using comfortable clothing and shoes), avoid hot and cold water

Urea creams 5-10\%

Moisturizing creams

Treatment: Urea creams 30\%; topic steroid creams

(hydrocortisone 1\%) and pain killers

Withold TKI treatment and resume it when grade $<1$

Surgical resection. Does not imply TKI termination

Pain killers

Corticosteroid therapy

Dose reduction

Low-molecular-weight heparin

Consider airway invasion assessment (with direct fibroscopy or imaging revision)

Electrocardiogram and electrolytes assessment before TKI start, 1-2 weeks after start, monthly for 3 months and then periodically

Correct any electrolyte abnormality

Avoid concomitant use of drugs that lead to QT

prolongation or monitor carefully (a comprehensive list of drugs that prolong QT can be found at www.

crediblemeds.org)

TKI withdrawal in case of QTC $>500$ ms or $>60 \mathrm{~ms}$ above baseline

Minor prolongation with sorafenib and lenvatinib

ALT, alanine aminotransferase; AST, aspartate aminotransferase; $\mathrm{CrCl}$, creatinine clearance.

progression has been reported after discontinuation of TKI treatment (Yun et al. 2014), and patients with progressive disease should not be left untreated for long periods of time. In patients who progress slowly during TKI treatment, the treatment may be maintained as long as there is evidence of clinical benefits. Alternatively, patients may benefit from another anti-angiogenic medication: after a first line with sorafenib, cabozantinib or lenvatinib given as second line was effective (Dadu et al. 2014, Massicotte et al. 2014, Schlumberger et al. 2015, Cabanillas et al. 2017), but benefits with another anti-angiogenic drug are questionable, and future studies should test cross-resistance between drugs. Alternatively, drugs targeted at genetic abnormalities that are present in the tumor tissue may be used, as well as immunotherapy. There is a need for trials, and recent trials performed in the frame of clinical networks have shown that inclusion of the expected number of thyroid cancer patients to reach statistically significant conclusions is possible in a limited period of time.
Declaration of interest

$A B, L L$ and $M K$ have nothing to declare. $S L$ has received honoraria for consulting from Astra Zeneca, Bayer and Sanofi-Genzyme, and grants for research from Sanofi-Genzyme. M S has received grants for research and honoraria for consulting from Astra Zeneca, Bayer, Eisai, Exelixis-IPSEN and Sanofi-Genzyme.

\section{Funding}

This work did not receive any specific grant from any funding agency in the public, commercial or not-for-profit sector.

\section{Acknowledgements}

This review corresponds to an invited lecture at the BES meeting in Harrogate by $M$ Schlumberger, as Clinical Endocrinology Trust Visiting Professor 2017.

\section{References}

Ahmed M, Barbachano Y, Riddell A, Hickey J, Newbold KL, Viros A, Harrington KJ, Marais R \& Nutting CM 2011 Analysis of the efficacy and toxicity of sorafenib in thyroid cancer: a phase II study in a UK
2018 Society for Endocrinology Published by Bioscientifica Ltd. Printed in Great Britain 
based population. European Journal of Endocrinology 165 315-322. (https://doi.org/10.1530/EJE-11-0129)

Azouzi N, Cailloux J, Cazarin JM, Knauf JA, Cracchiolo J, Al Ghuzlan A, Hartl D, Polak M, Carre A, El Mzibri M, et al. 2017 NADPH oxidase NOX4 is a critical mediator of BRAF(V600E)-induced downregulation of the sodium/iodide symporter in papillary thyroid carcinomas. Antioxidants and Redox Signaling 26 864-877. (https://doi. org/10.1089/ars.2015.6616)

Bass MB, Sherman SI, Schlumberger MJ, Davis MT, Kivman L, Khoo HM, Notari KH, Peach M, Hei YJ \& Patterson SD 2010 Biomarkers as predictors of response to treatment with motesanib in patients with progressive advanced thyroid cancer. Journal of Clinical Endocrinology and Metabolism 95 5018-5027. (https://doi.org/10.1210/jc.20100947)

Bastholt L, Schlumberger M, Fagin J, Wirth L, Elisei R, Sugitani I, Wu Y, Wang Z, Führer D, Weiss R, et al. 2016 Vandetanib in patients with locally advanced or metastatic differentiated thyroid cancer who are refractory or unsuitable for radioiodine therapy: a phase III study (VERIFY). In Annual Meeting of the European Thyroid Association. Copenhagen, Denmark: ETA.

Berdelou A, Borget I, Godbert Y, Nguyen T, Garcia ME, Chougnet CN, Ferru A, Buffet C, Chabre O, Huillard O, et al. 2017 Lenvatinib for the treatment of radioiodine-refractory thyroid cancer in real-life practice. Thyroid [epub]. (https://doi.org/10.1089/thy.2017.020)

Bernier MO, Leenhardt L, Hoang C, Aurengo A, Mary JY, Menegaux F, Enkaoua E, Turpin G, Chiras J, Saillant G, et al. 2001 Survival and therapeutic modalities in patients with bone metastases of differentiated thyroid carcinomas. Journal of Clinical Endocrinology and Metabolism 86 1568-1573. (https://doi.org/10.1210/ jcem.86.4.7390)

Bible KC, Suman VJ, Molina JR, Smallridge RC, Maples WJ, Menefee ME, Rubin J, Sideras K, Morris JC 3rd, McIver B, et al. 2010 Efficacy of pazopanib in progressive, radioiodine-refractory, metastatic differentiated thyroid cancers: results of a phase 2 consortium study. Lancet Oncology 11 962-972. (https://doi.org/10.1016/S14702045(10)70203-5)

Biondi B \& Wartofsky L 2014 Treatment with thyroid hormone. Endocrine Reviews 35 433-512. (https://doi.org/10.1210/er.2013-1083)

Blevins DP, Dadu R, Hu M, Baik C, Balachandran D, Ross W, Gunn B \& Cabanillas ME 2014 Aerodigestive fistula formation as a rare side effect of antiangiogenic tyrosine kinase inhibitor therapy for thyroid cancer. Thyroid 24 918-922. (https://doi.org/10.1089/thy.2012.0598)

Brose MS, Nutting CM, Jarzab B, Elisei R, Siena S, Bastholt L, de la Fouchardiere C, Pacini F, Paschke R, Shong YK, et al. 2014 Sorafenib in radioactive iodine-refractory, locally advanced or metastatic differentiated thyroid cancer: a randomised, double-blind, phase 3 trial. Lancet 384 319-328. (https://doi.org/10.1016/S01406736(14)60421-9)

Brose MS, Cabanillas ME, Cohen EE, Wirth LJ, Riehl T, Yue H, Sherman SI \& Sherman EJ 2016 Vemurafenib in patients with BRAF(V600E)-positive metastatic or unresectable papillary thyroid cancer refractory to radioactive iodine: a non-randomised, multicentre, open-label, phase 2 trial. Lancet Oncology 17 1272-1282. (https://doi.org/10.1016/S1470-2045(16)30166-8)

Brose MS, Smit J, Lin CC, Pitoia F, Fellous M, DeSanctis Y, Schlumberger M, Tori M \& Sugitani I 2017a Timing of multikinase inhibitor initiation in differentiated thyroid cancer. Endocrine-Related Cancer 24 237-242. (https://doi.org/10.1530/ERC-17-0016)

Brose MS, Worden FP, Newbold KL, Guo M \& Hurria A 2017b Effect of age on the efficacy and safety of lenvatinib in radioiodine-refractory differentiated thyroid cancer in the phase III SELECT trial. Journal of Clinical Oncology 35 2692-2699. (https://doi.org/10.1200/ JCO.2016.71.6472)

Bunone G, Vigneri P, Mariani L, Buto S, Collini P, Pilotti S, Pierotti MA \& Bongarzone I 1999 Expression of angiogenesis stimulators and inhibitors in human thyroid tumors and correlation with clinical pathological features. American Journal of Pathology 155 1967-1976. (https://doi.org/10.1016/S0002-9440(10)65515-0)

Cabanillas ME, Brose MS, Holland J, Ferguson KC \& Sherman SI 2014 A phase I study of cabozantinib (XL184) in patients with differentiated thyroid cancer. Thyroid 24 1508-1514. (https://doi.org/10.1089/ thy.2014.0125)

Cabanillas ME, Schlumberger M, Jarzab B, Martins RG, Pacini F, Robinson B, McCaffrey JC, Shah MH, Bodenner DL, Topliss D, et al. 2015 A phase 2 trial of lenvatinib (E7080) in advanced, progressive, radioiodine-refractory, differentiated thyroid cancer: a clinical outcomes and biomarker assessment. Cancer 121 2749-2756. (https://doi.org/10.1002/cncr.29395)

Cabanillas ME, de Souza JA, Geyer S, Wirth LJ, Menefee ME, Liu SV, Shah K, Wright J \& Shah MH 2017 Cabozantinib as salvage therapy for patients with tyrosine kinase inhibitor-refractory differentiated thyroid cancer: results of a multicenter phase II International Thyroid Oncology Group trial. Journal of Clinical Oncology 35 3315-3321. (https://doi.org/10.1200/JCO.2017.73.0226)

Caillou B, Talbot M, Weyemi U, Pioche-Durieu C, Al Ghuzlan A, Bidart JM, Chouaib S, Schlumberger M \& Dupuy C 2011 Tumorassociated macrophages (TAMs) form an interconnected cellular supportive network in anaplastic thyroid carcinoma. PLOS ONE 6 e22567. (https://doi.org/10.1371/journal.pone.0022567)

Capdevila J, Iglesias L, Halperin I, Segura A, Martinez-Trufero J, Vaz MA, Corral J, Obiols G, Grande E, Grau JJ, et al. 2012 Sorafenib in metastatic thyroid cancer. Endocrine-Related Cancer 19 209-216. (https://doi.org/10.1530/ERC-11-0351)

Cancer Genome Atlas Research Network 2014 Integrated genomic characterization of papillary thyroid carcinoma. Cell 159 676-690.

Carr LL, Mankoff DA, Goulart BH, Eaton KD, Capell PT, Kell EM, Bauman JE \& Martins RG 2010 Phase II study of daily sunitinib in FDG-PET-positive, iodine-refractory differentiated thyroid cancer and metastatic medullary carcinoma of the thyroid with functional imaging correlation. Clinical Cancer Research 16 5260-5268. (https:// doi.org/10.1158/1078-0432.CCR-10-0994)

Casara D, Rubello D, Saladini G, Masarotto G, Favero A, Girelli ME \& Busnardo B 1993 Different features of pulmonary metastases in differentiated thyroid cancer: natural history and multivariate statistical analysis of prognostic variables. Journal of Nuclear Medicine 34 1626-1631.

Cohen EE, Rosen LS, Vokes EE, Kies MS, Forastiere AA, Worden FP, Kane MA, Sherman E, Kim S, Bycott P, et al. 2008 Axitinib is an active treatment for all histologic subtypes of advanced thyroid cancer: results from a phase II study. Journal of Clinical Oncology 26 4708-4713. (https://doi.org/10.1200/JCO.2007.15.9566)

Coleman R, Gnant M, Morgan G \& Clezardin P 2012 Effects of bonetargeted agents on cancer progression and mortality. Journal of the National Cancer Institute 104 1059-1067. (https://doi.org/10.1093/ jnci/djs263)

Crouzeix G, Michels JJ, Sevin E, Aide N, Vaur D \& Bardet S 2012 Unusual short-term complete response to two regimens of cytotoxic chemotherapy in a patient with poorly differentiated thyroid carcinoma. Journal of Clinical Endocrinology and Metabolism 97 3046-3050. (https://doi.org/10.1210/jc.2012-1630)

Dadu R, Devine C, Hernandez M, Waguespack SG, Busaidy NL, Hu MI, Jimenez C, Habra MA, Sellin RV, Ying AK, et al. 2014 Role of salvage targeted therapy in differentiated thyroid cancer patients who failed first-line sorafenib. Journal of Clinical Endocrinology and Metabolism 99 2086-2094. (https://doi. org/10.1210/jc.2013-3588)

Dadu R, Shah K, Busaidy NL, Waguespack SG, Habra MA, Ying AK, Hu MI, Bassett R, Jimenez C, Sherman SI, et al. 2015 Efficacy and tolerability of vemurafenib in patients with BRAF(V600E)-positive papillary thyroid cancer: M.D. Anderson Cancer Center off label experience. Journal of Clinical Endocrinology and Metabolism 100 E77E81. (https://doi.org/10.1210/jc.2014-2246)
(2) 2018 Society for Endocrinology Published by Bioscientifica Ltd. Printed in Great Britain 
Deandreis D, Al Ghuzlan A, Leboulleux S, Lacroix L, Garsi JP, Talbot M, Lumbroso J, Baudin E, Caillou B, Bidart JM, et al. 2011a Do histological, immunohistochemical, and metabolic (radioiodine and fluorodeoxyglucose uptakes) patterns of metastatic thyroid cancer correlate with patient outcome? Endocrine-Related Cancer 18 159-169. (https://doi.org/10.1677/ERC-10-0233)

Deandreis D, Leboulleux S, Dromain C, Auperin A, Coulot J, Lumbroso J, Deschamps F, Rao P, Schlumberger M \& de Baere T $2011 b$ Role of FDG PET/CT and chest CT in the follow-up of lung lesions treated with radiofrequency ablation. Radiology 258 270-276. (https://doi.org/10.1148/radiol.10092440)

Deandreis D, Rubino C, Tala H, Leboulleux S, Terroir M, Baudin E, Larson S, Fagin JA, Schlumberger M \& Tuttle RM 2017 Comparison of empiric versus whole-body/-blood clearance dosimetry-based approach to radioactive iodine treatment in patients with metastases from differentiated thyroid cancer. Journal of Nuclear Medicine $\mathbf{5 8}$ 717-722. (https://doi.org/10.2967/jnumed.116.179606)

Di Maio M, Gallo C, Leighl NB, Piccirillo MC, Daniele G, Nuzzo F, Gridelli C, Gebbia V, Ciardiello F, De Placido S, et al. 2015 Symptomatic toxicities experienced during anticancer treatment: agreement between patient and physician reporting in three randomized trials. Journal of Clinical Oncology 33 910-915. (https:// doi.org/10.1200/JCO.2014.57.9334)

Durante C, Haddy N, Baudin E, Leboulleux S, Hartl D, Travagli JP, Caillou B, Ricard M, Lumbroso JD, De Vathaire F, et al. 2006 Longterm outcome of 444 patients with distant metastases from papillary and follicular thyroid carcinoma: benefits and limits of radioiodine therapy. Journal of Clinical Endocrinology and Metabolism 91 2892-2899. (https://doi.org/10.1210/jc.2005-2838)

Durante C, Puxeddu E, Ferretti E, Morisi R, Moretti S, Bruno R, Barbi F, Avenia N, Scipioni A, Verrienti A, et al. 2007 BRAF mutations in papillary thyroid carcinomas inhibit genes involved in iodine metabolism. Journal of Clinical Endocrinology and Metabolism 92 2840-2843. (https://doi.org/10.1210/jc.2006-2707)

Durante C, Tallini G, Puxeddu E, Sponziello M, Moretti S, Ligorio C, Cavaliere A, Rhoden KJ, Verrienti A, Maranghi M, et al. 2011 $\mathrm{BRAF}(\mathrm{V} 600 \mathrm{E})$ mutation and expression of proangiogenic molecular markers in papillary thyroid carcinomas. European Journal of Endocrinology 165 455-463. (https://doi.org/10.1530/EJE-11-0283)

Eisenhauer EA, Therasse P, Bogaerts J, Schwartz LH, Sargent D, Ford R, Dancey J, Arbuck S, Gwyther S, Mooney M, et al. 2009 New response evaluation criteria in solid tumours: revised RECIST guideline (version 1.1). European Journal of Cancer 45 228-247. (https://doi. org/10.1016/j.ejca.2008.10.026)

Fagin JA \& Wells SA Jr 2016 Biologic and clinical perspectives on thyroid cancer. New England Journal of Medicine 375 1054-1067. (https://doi.org/10.1056/NEJMra1501993)

Falchook GS, Millward M, Hong D, Naing A, Piha-Paul S, Waguespack SG, Cabanillas ME, Sherman SI, Ma B, Curtis M, et al. 2015 BRAF inhibitor dabrafenib in patients with metastatic BRAFmutant thyroid cancer. Thyroid 25 71-77. (https://doi.org/10.1089/ thy.2014.0123)

Farooki A, Leung V, Tala H \& Tuttle RM 2012 Skeletal-related events due to bone metastases from differentiated thyroid cancer. Journal of Clinical Endocrinology and Metabolism 97 2433-2439. (https://doi. org/10.1210/jc.2012-1169)

Gupta-Abramson V, Troxel AB, Nellore A, Puttaswamy K, Redlinger M, Ransone K, Mandel SJ, Flaherty KT, Loevner LA, O'Dwyer PJ, et al. 2008 Phase II trial of sorafenib in advanced thyroid cancer. Journal of Clinical Oncology 26 4714-4719. (https://doi.org/10.1200/ JCO.2008.16.3279)

Haugen BR, Alexander EK, Bible KC, Doherty GM, Mandel SJ, Nikiforov YE, Pacini F, Randolph GW, Sawka AM, Schlumberger M, et al. 20162015 American Thyroid Association Management Guidelines for adult patients with thyroid nodules and differentiated thyroid cancer: the American Thyroid Association Guidelines task force on thyroid nodules and differentiated thyroid cancer. Thyroid 26 1-133. (https://doi.org/10.1089/thy.2015.0020)

Ho AL, Grewal RK, Leboeuf R, Sherman EJ, Pfister DG, Deandreis D, Pentlow KS, Zanzonico PB, Haque S, Gavane S, et al. 2013 Selumetinib-enhanced radioiodine uptake in advanced thyroid cancer. New England Journal of Medicine 368 623-632. (https://doi. org/10.1056/NEJMoa1209288)

Hoftijzer H, Heemstra KA, Morreau H, Stokkel MP, Corssmit EP, Gelderblom H, Weijers K, Pereira AM, Huijberts M, Kapiteijn E, et al. 2009 Beneficial effects of sorafenib on tumor progression, but not on radioiodine uptake, in patients with differentiated thyroid carcinoma. European Journal of Endocrinology 161 923-931. (https:// doi.org/10.1530/EJE-09-0702)

Kelly LM, Barila G, Liu P, Evdokimova VN, Trivedi S, Panebianco F, Gandhi M, Carty SE, Hodak SP, Luo J, et al. 2014 Identification of the transforming STRN-ALK fusion as a potential therapeutic target in the aggressive forms of thyroid cancer. PNAS $1114233-4238$. (https://doi.org/10.1073/pnas.1321937111)

Kitamura Y, Shimizu K, Nagahama M, Sugino K, Ozaki O, Mimura T, Ito K \& Tanaka S 1999 Immediate causes of death in thyroid carcinoma: clinicopathological analysis of 161 fatal cases. Journal of Clinical Endocrinology and Metabolism 84 4043-4049. (https://doi. org/10.1210/jcem.84.11.6115)

Kloos RT, Ringel MD, Knopp MV, Hall NC, King M, Stevens R, Liang J, Wakely PE Jr, Vasko VV, Saji M, et al. 2009 Phase II trial of sorafenib in metastatic thyroid cancer. Journal of Clinical Oncology 27 1675-1684. (https://doi.org/10.1200/JCO.2008.18.2717)

Klubo-Gwiezdzinska J, Van Nostrand D, Atkins F, Burman K, Jonklaas J, Mete M \& Wartofsky L 2011 Efficacy of dosimetric versus empiric prescribed activity of 131I for therapy of differentiated thyroid cancer. Journal of Clinical Endocrinology and Metabolism 96 3217-3225. (https://doi.org/10.1210/jc.2011-0494)

Lamartina L, Ippolito S, Danis M, Bidault F, Borget I, Berdelou A, Al Ghuzlan A, Hartl D, Blanchard P, Terroir M, et al. 2016 Antiangiogenic tyrosine kinase inhibitors: occurrence and risk factors of hemoptysis in refractory thyroid cancer. Journal of Clinical Endocrinology and Metabolism 101 2733-2741. (https://doi. org/10.1210/jc.2015-4391)

Leboulleux S, Bastholt L, Krause T, de la Fouchardiere C, Tennvall J, Awada A, Gomez JM, Bonichon F, Leenhardt L, Soufflet C, et al. 2012 Vandetanib in locally advanced or metastatic differentiated thyroid cancer: a randomised, double-blind, phase 2 trial. Lancet Oncology 13 897-905. (https://doi.org/10.1016/S1470-2045(12)70335-2)

Locati LD, Licitra L, Agate L, Ou SH, Boucher A, Jarzab B, Qin S, Kane MA, Wirth LJ, Chen C, et al. 2014 Treatment of advanced thyroid cancer with axitinib: phase 2 study with pharmacokinetic/ pharmacodynamic and quality-of-life assessments. Cancer 120 2694-2703. (https://doi.org/10.1002/cncr.28766)

Massicotte MH, Brassard M, Claude-Desroches M, Borget I, Bonichon F, Giraudet AL, Do Cao C, Chougnet CN, Leboulleux S, Baudin E, et al. 2014 Tyrosine kinase inhibitor treatments in patients with metastatic thyroid carcinomas: a retrospective study of the TUTHYREF network. European Journal of Endocrinology 170 575-582. (https://doi. org/10.1530/EJE-13-0825)

Maxon HR, Thomas SR, Hertzberg VS, Kereiakes JG, Chen IW, Sperling MI \& Saenger EL 1983 Relation between effective radiation dose and outcome of radioiodine therapy for thyroid cancer. New England Journal of Medicine 309 937-941. (https://doi.org/10.1056/ NEJM198310203091601)

Mehnert JM, Varga A, Brose M, Aggarwal RR, Lin C-C, Prawira A, Braud Fd, Tamura K, Doi T, Piha-Paul SA, et al. 2016 Pembrolizumab for advanced papillary or follicular thyroid cancer: preliminary results from the phase 1b KEYNOTE-028 study. Journal of Clinical Oncology 346091.

Miyauchi A, Kudo T, Miya A, Kobayashi K, Ito Y, Takamura Y, Higashiyama T, Fukushima M, Kihara M, Inoue H, et al. 2011 (c) 2018 Society for Endocrinology Published by Bioscientifica Ltd. Printed in Great Britain 
Prognostic impact of serum thyroglobulin doubling-time under thyrotropin suppression in patients with papillary thyroid carcinoma who underwent total thyroidectomy. Thyroid 21 707-716. (https:// doi.org/10.1089/thy.2010.0355)

Nagarajah J, Ho AL, Tuttle RM, Weber WA \& Grewal RK 2015 Correlation of BRAFV600E mutation and glucose metabolism in thyroid cancer patients: an (1)(8)F-FDG PET study. Journal of Nuclear Medicine 56 662-667. (https://doi.org/10.2967/ jnumed.114.150607)

Nascimento C, Borget I, Al Ghuzlan A, Deandreis D, Hartl D, Lumbroso J, Berdelou A, Lepoutre-Lussey C, Mirghani H, Baudin E, et al. 2015 Postoperative fluorine-18-fluorodeoxyglucose positron emission tomography/computed tomography: an important imaging modality in patients with aggressive histology of differentiated thyroid cancer. Thyroid 25 437-444. (https://doi.org/10.1089/ thy.2014.0320)

Network CGAR 2014 Integrated genomic characterization of papillary thyroid carcinoma. Cell 159 676-690. (https://doi.org/10.1016/j. cell.2014.09.050)

Ott PA, Hodi FS \& Robert C 2013 CTLA-4 and PD-1/PD-L1 blockade: new immunotherapeutic modalities with durable clinical benefit in melanoma patients. Clinical Cancer Research 19 5300-5309. (https:// doi.org/10.1158/1078-0432.CCR-13-0143)

Padovani RP, Kasamatsu TS, Nakabashi CC, Camacho CP, Andreoni DM, Malouf EZ, Marone MM, Maciel RM \& Biscolla RP 2012 One month is sufficient for urinary iodine to return to its baseline value after the use of water-soluble iodinated contrast agents in post-thyroidectomy patients requiring radioiodine therapy. Thyroid 22 926-930. (https:// doi.org/10.1089/thy.2012.0099)

Phay JE \& Ringel MD 2013 Metastatic mechanisms in follicular cellderived thyroid cancer. Endocrine-Related Cancer 20 R307-R319. (https://doi.org/10.1530/ERC-13-0187)

Plyku D, Hobbs RF, Huang K, Atkins F, Garcia C, Sgouros G \& Van Nostrand D 2017 Recombinant human thyroid-stimulating hormone versus thyroid hormone withdrawal in (124)I PET/CT-based dosimetry for (131)I therapy of metastatic differentiated thyroid cancer. Journal of Nuclear Medicine 58 1146-1154. (https://doi. org/10.2967/jnumed.116.179366)

Potzi C, Moameni A, Karanikas G, Preitfellner J, Becherer A, Pirich C \& Dudczak R 2006 Comparison of iodine uptake in tumour and nontumour tissue under thyroid hormone deprivation and with recombinant human thyrotropin in thyroid cancer patients. Clinical Endocrinology 65 519-523. (https://doi. org/10.1111/j.1365-2265.2006.02626.x)

Quan GM, Pointillart V, Palussiere J \& Bonichon F 2012

Multidisciplinary treatment and survival of patients with vertebral metastases from thyroid carcinoma. Thyroid 22 125-130. (https://doi. org/10.1089/thy.2010.0248)

Ricarte-Filho JC, Ryder M, Chitale DA, Rivera M, Heguy A, Ladanyi M, Janakiraman M, Solit D, Knauf JA, Tuttle RM, et al. 2009 Mutational profile of advanced primary and metastatic radioactive iodinerefractory thyroid cancers reveals distinct pathogenetic roles for BRAF, PIK3CA, and AKT1. Cancer Research 69 4885-4893. (https:// doi.org/10.1158/0008-5472.CAN-09-0727)

Ringel MD, Hayre N, Saito J, Saunier B, Schuppert F, Burch H, Bernet V, Burman KD, Kohn LD \& Saji M 2001 Overexpression and overactivation of Akt in thyroid carcinoma. Cancer Research $\mathbf{6 1}$ 6105-6111.

Rivera M, Ghossein RA, Schoder H, Gomez D, Larson SM \& Tuttle RM 2008 Histopathologic characterization of radioactive iodinerefractory fluorodeoxyglucose-positron emission tomography-positive thyroid carcinoma. Cancer 113 48-56. (https://doi.org/10.1002/ cncr.23515)

Rivkees SA, Mazzaferri EL, Verburg FA, Reiners C, Luster M, Breuer CK, Dinauer CA \& Udelsman R 2011 The treatment of differentiated thyroid cancer in children: emphasis on surgical approach and radioactive iodine therapy. Endocrine Reviews 32 798-826. (https:// doi.org/10.1210/er.2011-0011)

Robbins RJ, Wan Q, Grewal RK, Reibke R, Gonen M, Strauss HW, Tuttle RM, Drucker W \& Larson SM 2006 Real-time prognosis for metastatic thyroid carcinoma based on 2-[18F]fluoro-2-deoxy-Dglucose-positron emission tomography scanning. Journal of Clinical Endocrinology and Metabolism 91 498-505. (https://doi.org/10.1210/ jc.2005-1534)

Robenshtok E, Farooki A, Grewal RK \& Tuttle RM 2014 Natural history of small radioiodine-avid bone metastases that have no structural correlate on imaging studies. Endocrine 47 266-272. (https://doi. org/10.1007/s12020-013-0123-8)

Robinson B, Schlumberger M, Wirth LJ, Dutcus CE, Song J, Taylor MH, Kim SB, Krzyzanowska MK, Capdevila J, Sherman SI, et al. 2016 Characterization of tumor size changes over time from the phase 3 study of lenvatinib in thyroid cancer. Journal of Clinical Endocrinology and Metabolism 101 4103-4109. (https://doi.org/10.1210/jc.20153989)

Rothenberg SM, McFadden DG, Palmer EL, Daniels GH \& Wirth LJ 2015 Redifferentiation of iodine-refractory BRAF V600E-mutant metastatic papillary thyroid cancer with dabrafenib. Clinical Cancer Research 21 1028-1035. (https://doi.org/10.1158/1078-0432.CCR-14-2915)

Rubino C, de Vathaire F, Dottorini ME, Hall P, Schvartz C, Couette JE, Dondon MG, Abbas MT, Langlois C \& Schlumberger M 2003 Second primary malignancies in thyroid cancer patients. British Journal of Cancer 89 1638-1644. (https://doi.org/10.1038/sj.bjc.6601319)

Ruegemer JJ, Hay ID, Bergstralh EJ, Ryan JJ, Offord KP \& Gorman CA 1988 Distant metastases in differentiated thyroid carcinoma: a multivariate analysis of prognostic variables. Journal of Clinical Endocrinology and Metabolism 67 501-508. (https://doi.org/10.1210/ jcem-67-3-501)

Ryder M, Ghossein RA, Ricarte-Filho JC, Knauf JA \& Fagin JA 2008 Increased density of tumor-associated macrophages is associated with decreased survival in advanced thyroid cancer. Endocrine-Related Cancer 15 1069-1074. (https://doi.org/10.1677/ERC-08-0036)

Ryder M, Gild M, Hohl TM, Pamer E, Knauf J, Ghossein R, Joyce JA \& Fagin JA 2013 Genetic and pharmacological targeting of CSF-1/ CSF-1R inhibits tumor-associated macrophages and impairs BRAFinduced thyroid cancer progression. PLOS ONE 8 e54302. (https:// doi.org/10.1371/journal.pone.0054302)

Sabra MM, Grewal RK, Tala H, Larson SM \& Tuttle RM 2012 Clinical outcomes following empiric radioiodine therapy in patients with structurally identifiable metastatic follicular cell-derived thyroid carcinoma with negative diagnostic but positive post-therapy 131 whole-body scans. Thyroid 22 877-883. (https://doi.org/10.1089/ thy.2011.0429)

Schlumberger M, Lacroix L, Russo D, Filetti S \& Bidart JM $2007 a$ Defects in iodide metabolism in thyroid cancer and implications for the follow-up and treatment of patients. Nature Clinical Practice: Endocrinology and Metabolism 3 260-269. (https://doi.org/10.1038/ ncpendmet0449)

Schlumberger M, Ricard M, De Pouvourville G \& Pacini F 2007b How the availability of recombinant human TSH has changed the management of patients who have thyroid cancer. Nature Clinical Practice: Endocrinology and Metabolism 3 641-650. (https://doi. org/10.1038/ncpendmet0594)

Schlumberger M, Brose M, Elisei R, Leboulleux S, Luster M, Pitoia F \& Pacini F 2014 Definition and management of radioactive iodinerefractory differentiated thyroid cancer. Lancet Diabetes and Endocrinology 2 356-358. (https://doi.org/10.1016/S22138587(13)70215-8)

Schlumberger M, Tahara M, Wirth LJ, Robinson B, Brose MS, Elisei R, Habra MA, Newbold K, Shah MH, Hoff AO, et al. 2015 Lenvatinib versus placebo in radioiodine-refractory thyroid cancer. New England Journal of Medicine 372 621-630. (https://doi.org/10.1056/ NEJMoa1406470)
(2) 2018 Society for Endocrinology Published by Bioscientifica Ltd. Printed in Great Britain 
Sgouros G, Kolbert KS, Sheikh A, Pentlow KS, Mun EF, Barth A, Robbins RJ \& Larson SM 2004 Patient-specific dosimetry for 131I thyroid cancer therapy using 124I PET and 3-dimensional-internal dosimetry (3D-ID) software. Journal of Nuclear Medicine $\mathbf{4 5}$ 1366-1372.

Sherman SI 2010 Cytotoxic chemotherapy for differentiated thyroid carcinoma. Clinical Oncology 22 464-468. (https://doi.org/10.1016/j. clon.2010.03.014)

Sherman SI, Wirth LJ, Droz JP, Hofmann M, Bastholt L, Martins RG, Licitra L, Eschenberg MJ, Sun YN, Juan T, et al. 2008 Motesanib diphosphate in progressive differentiated thyroid cancer. New England Journal of Medicine 359 31-42. (https://doi.org/10.1056/ NEJMoa075853)

Spano JP, Vano Y, Vignot S, De La Motte Rouge T, Hassani L, Mouawad R, Menegaux F, Khayat D \& Leenhardt L 2012 GEMOX regimen in the treatment of metastatic differentiated refractory thyroid carcinoma. Medical Oncology 29 1421-1428. (https://doi. org/10.1007/s12032-011-0070-2)

Tahara M, Schlumberger M, Elisei R, Habra MA, Kiyota N, Paschke R, Dutcus CE, Hihara T, McGrath S, Matijevic M, et al. 2017 Exploratory analysis of biomarkers associated with clinical outcomes from the study of lenvatinib in differentiated cancer of the thyroid. European Journal of Cancer 75 213-221. (https://doi.org/10.1016/j. ejca.2017.01.013)

Tala H, Robbins R, Fagin JA, Larson SM \& Tuttle RM 2011 Five-year survival is similar in thyroid cancer patients with distant metastases prepared for radioactive iodine therapy with either thyroid hormone withdrawal or recombinant human TSH. Journal of Clinical Endocrinology and Metabolism 96 2105-2111. (https://doi. org/10.1210/jc.2011-0305)

Tallet AV, Dhermain F, Le Rhun E, Noel G \& Kirova YM 2017 Combined irradiation and targeted therapy or immune checkpoint blockade in brain metastases: toxicities and efficacy. Annals of Oncology $\mathbf{2 8}$ 2962-2976. (https://doi.org/10.1093/annonc/mdx408)

Terroir M, Borget I, Bidault F, Ricard M, Deschamps F, Hartl D, Tselikas L, Dercle L, Lumbroso J, Baudin E, et al. 2017 The intensity of 18FDG uptake does not predict tumor growth in patients with metastatic differentiated thyroid cancer. European Journal of Nuclear
Medicine and Molecular Imaging 44 638-646. (https://doi.org/10.1007/ s00259-016-3551-x)

Thies ED, Tanase K, Maeder U, Luster M, Buck AK, Hanscheid H, Reiners C \& Verburg FA 2014 The number of 131I therapy courses needed to achieve complete remission is an indicator of prognosis in patients with differentiated thyroid carcinoma. European Journal of Nuclear Medicine and Molecular Imaging 41 2281-2290. (https://doi. org/10.1007/s00259-014-2851-2)

Tuttle RM, Brose MS, Grande E, Kim SW, Tahara M \& Sabra MM 2017 Novel concepts for initiating multitargeted kinase inhibitors in radioactive iodine refractory differentiated thyroid cancer. Best Practice and Research Clinical Endocrinology and Metabolism 31 295-305. (https://doi.org/10.1016/j.beem.2017.04.014)

Vaisman F, Tala H, Grewal R \& Tuttle RM 2011 In differentiated thyroid cancer, an incomplete structural response to therapy is associated with significantly worse clinical outcomes than only an incomplete thyroglobulin response. Thyroid 21 1317-1322. (https://doi. org/10.1089/thy.2011.0232)

Voce P, D'Agostino M, Moretti S, Sponziello M, Rhoden K, Calcinaro F, Tamburrano G, Tallini G, Puxeddu E, Filetti S, et al. 2011 Sunitinib inhibits tumor vascularity and growth but does not affect Akt and ERK phosphorylation in xenograft tumors. Oncology Reports 26 1075-1080. (https://doi.org/10.3892/or.2011.1422)

Wardley A, Davidson N, Barrett-Lee P, Hong A, Mansi J, Dodwell D, Murphy R, Mason T \& Cameron D 2005 Zoledronic acid significantly improves pain scores and quality of life in breast cancer patients with bone metastases: a randomised, crossover study of community vs hospital bisphosphonate administration. British Journal of Cancer 92 1869-1876. (https://doi.org/10.1038/sj. bjc.6602551)

Xing M 2010 Genetic alterations in the phosphatidylinositol-3 kinase/ Akt pathway in thyroid cancer. Thyroid 20 697-706. (https://doi. org/10.1089/thy.2010.1646)

Yun KJ, Kim W, Kim EH, Kim MH, Lim DJ, Kang MI \& Cha BY 2014 Accelerated disease progression after discontinuation of sorafenib in a patient with metastatic papillary thyroid cancer. Endocrinology and Metabolism 29 388-393. (https://doi.org/10.3803/ EnM.2014.29.3.388)

Received in final form 11 December 2017

Accepted 25 January 2018

Accepted Preprint published online 25 January 2018 (c) 2018 Society for Endocrinology Published by Bioscientifica Ltd. Printed in Great Britain 